\title{
ArcheoSciences
}

Revue d'archéométrie

33 (suppl.) | 2009

Mémoire du sol, espace des hommes

\section{Archaeological geophysical prospection in peatland environments: Case studies and suggestions for future practice}

Kayt Armstrong, Tim Darvill and Paul Cheetham

\section{CpenEdition}

\section{Journals}

Electronic version

URL: https://journals.openedition.org/archeosciences/1646

DOI: 10.4000/archeosciences. 1646

ISBN: 978-2-7535-1599-4

ISSN: $2104-3728$

Publisher

Presses universitaires de Rennes

\section{Printed version}

Date of publication: 30 October 2009

Number of pages: 251-253

ISBN: 978-2-7535-0943-6

ISSN: 1960-1360

\section{Electronic reference}

Kayt Armstrong, Tim Darvill and Paul Cheetham, "Archaeological geophysical prospection in peatland environments: Case studies and suggestions for future practice", ArcheoSciences [Online], 33 (suppl.) I 2009, Online since 30 October 2011, connection on 01 February 2022. URL: http://

journals.openedition.org/archeosciences/1646 ; DOI: https://doi.org/10.4000/archeosciences.1646 


\title{
Archaeological geophysical prospection in peatland environments: Case studies and suggestions for future practice
}

\author{
Kayt Armstrong*, Tim Darvill* and Paul Cheetham*
}

Key words: Peatland, Ground Penetrating Radar, Frequency domain EM, Resistivity, Magnetometry.

Peatland environments, in contrast to 'dry-land' sites, preserve organic material, including anthropogenic objects, because they are anaerobic, and are therefore of great importance to archaeology. Peat also preserves macro- and micropaleoenvironmental evidence and is the primary resource for understanding past climates and ecology. Archaeological sites often lie within or at the base of wet, deep, homogenous peat rendering them invisible to surface observers. As a result, they most often come to light whilst being destroyed. Once located, they are difficult and time-consuming to excavate, leading to a bias towards small but detailed excavations. Furthermore, these sites and the environments they inhabit are very sensitive to localised small-scale environmental change, so invasive evaluation techniques are ruled out. There is a need for non-invasive techniques to detect, monitor, and situate peatland sites within their wider context. A research project to evaluate the use of geophysical prospection for this purpose is being undertaken at Bournemouth University. In the past it has been suggested that peat deposits are too wet, too deep, too homogenous or too similar to the target for traditional dry-land geophysical techniques to be of much use (English Heritage 2008).

The project has defined four peatland environments: upland and lowland, each divided into sites with sub peat and intra peat archaeological deposits. The split between upland and lowland might seem very simple considering the complex classification schemes employed in conservation, geography and biology, but is based on a distinction made by the Soil Survey of England and Wales, and widely used by archaeologists in planning and strategy documents. Eight case study sites were selected to represent these different environments. Two are sites on the Carn Meini outcroppings in Pembrokeshire, two are on Dartmoor, two are in the Somerset Levels and two are in the Flag Fen landscape of the East Anglian Fens (Fig. 1). All the case study sites were surveyed with GPR (MALA RAMAC GPR with 500 $\mathrm{MHz}$ and $250 \mathrm{MHz}$ antennae, resistivity (including multiplexed surveys on the lowland sites, allowing resistance tomography, using an RM15A and MPX15), frequency domain electromagnetic (EM38B) and gradiometry (FM36 and Bartington Grad601). This approach was selected to test the responses at representative sites to different but widely available techniques and instruments, rather than focusing on one particular system, or developing new technologies. Each case study was also selected with specific archaeological questions in mind, as well as the more general issue of detection. The ability of the geophysical results to answer these questions was used, in part, to measure the success of the various techniques. Methods for comparing different geophysical techniques, following Kvamme (2006) were also

*Bournemouth University. (karmstrong@bournemouth).(ac.uk tdarvill@bournemouth.ac.uk), (pcheetham@bournemouth.ac.uk) 


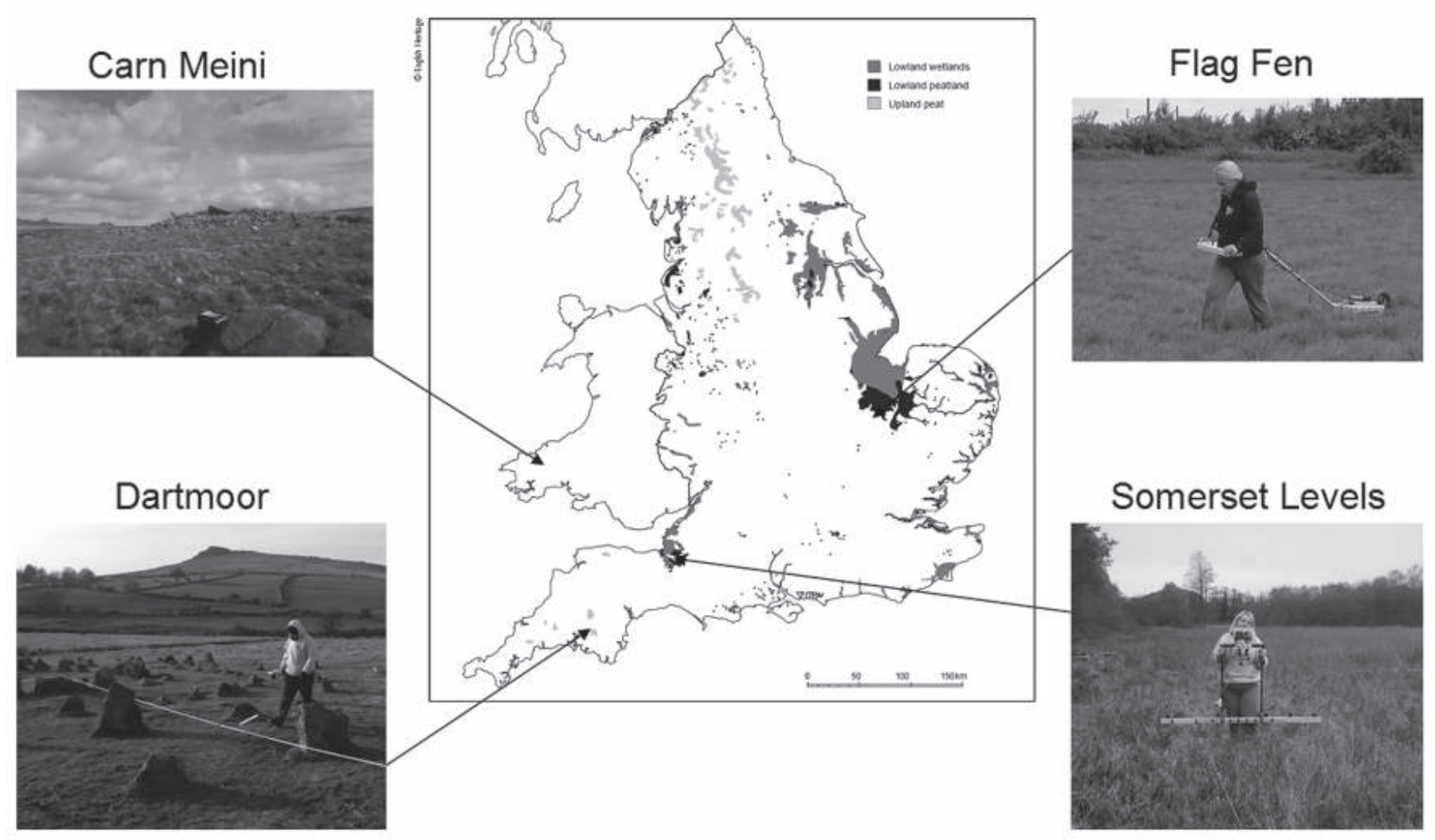

Figure 1: Case Study Locations. Map from Van de Noort et al (2002, 7).

used to compare the survey outcomes and assist in making judgements about the strengths and weaknesses of them in different environments.

The upland case studies, in Pembrokeshire and on Dartmoor have demonstrated that geophysical survey on the more shallow types of upland peat using conventional techniques, can yield useful information about prehistoric sites to guide preservation strategies and deal with specific research questions about the past. The situation in the lowlands is more complex. In the Somerset Levels surveys have identified anomalies that correspond to the location of the Sweet Track, a Neolithic trackway through the Brue Valley (Fig. 2). Interestingly and unexpectedly, these anomalies were visible in the gradiometer and resistivity data, as well as in the radar. In contrast, at Flag Fen two separate surveys failed to locate any of the substantial Bronze Age timbers on the site. They did reveal information about the more recent landscape history though, showing that geophysical techniques can reveal archaeologically useful information about lowland peatland sites, even when the peat has become desiccated at the surface and the landscape has been subjected to drainage and agricultural exploitation (Fig. 3).
The case studies demonstrate that there are detectable differences within these environments that are archaeologically informative, but that they present new interpretative challenges, especially in lowland peat environments. Qualitative comparisons of the results have enabled conclusions about which techniques are best suited to each environment, and about optimum survey conditions and practice. Radar works best on lowland sites that are saturated or where the archaeology is shallow, but fails where there is a pronounced desiccated zone or interleaving alluvial deposits. It has been possible to identify anomalies apparently associated with waterlogged wood in radar, EM, RM15 and FM36 data. At present it is hypothesized that these anomalies arise due to the specific geochemistry of the site in question and the wood forming a hydrological barrier. In the uplands, conventional techniques give informative responses, more comparable to 'dry-land' sites.

At three of the sites ground truthing excavations have been undertaken. This paper presents the preliminary results from the case studies, ground truthing work and the general conclusions of the research project, including recommendations for future practice. 


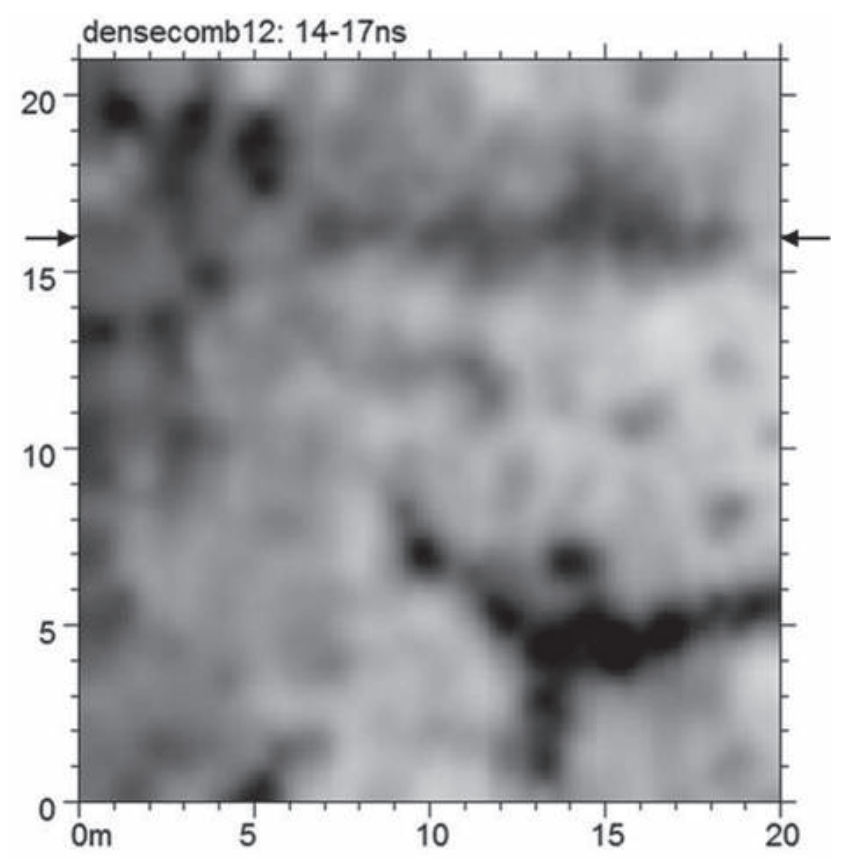

Figure 2: GPR Timeslice (14-17 nS) from $250 \mathrm{MHz}$ survey at Shapwick Heath, Somerset Levels. marked anomaly corresponds to the known location of the Sweet Track, the dendritic anomaly is thought to be a bog oak. Darker colours represent higher amplitudes, scales are in metres.

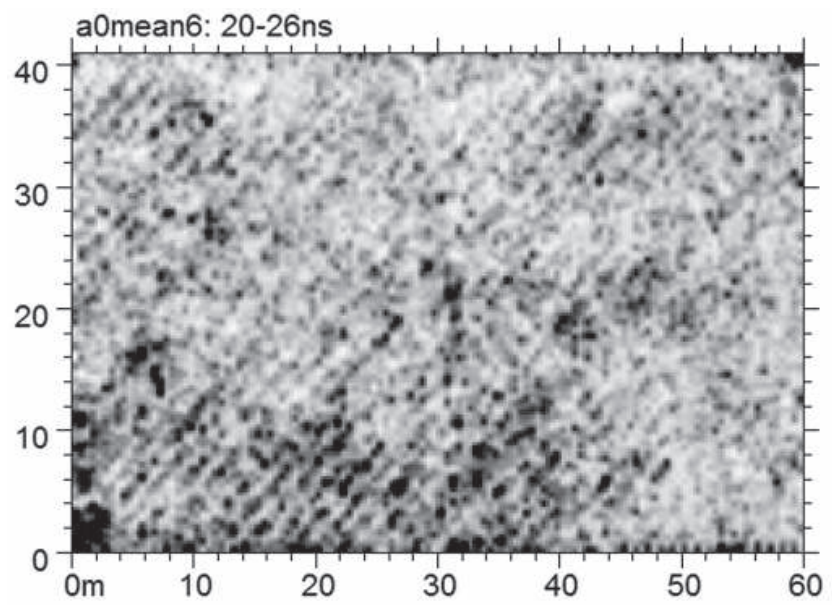

Figure 3: GPR Timeslice (20-26nS) from 250MHz survey at Flag Fen showing previous land use (either cultivation or peat workings) not visible from the surface features and on a different alignment to the recorded field system. Scales as Figure 2.

\section{Acknowledgements}

This research project is supervised by Prof. Darvill and Paul Cheetham and funded by a Bournemouth University PhD Studentship. English Heritage funded the ground truthing work on Dartmoor. English Heritage, Natural England, the Dartmoor National Park Authority, several county archaeologists and landowners gave permissions, advice and support. Finally, a big thank you to the many friends and students who assisted with fieldwork.

\section{References}

English Heritage, 2008. Geophysical Survey in Archaeological Field Evaluation (2nd Edition). 2nd ed. Swindon: English Heritage. 